\title{
THE WIDTH OF EDGE EFFECTS OF ROAD CONSTRUCTION ON FAUNA AND ECOLOGICALLY CRITICAL ROAD DENSITY
}

\author{
Shyh-Chyang LIN \\ Department of Civil Engineering and Engineering Management, National Quemoy University, \\ Jinning, Kinmen, Taiwan
}

Submitted 02 Jan. 2015; accepted 20 May 2015

\begin{abstract}
This study investigates the ecological impacts of road construction by trapping rodents, invertebrates, and amphibians with wire-mesh traps and pitfalls along a road under construction on Kinmen island, Taiwan. The capture data show that the Brown country rat's (Rattus losea) edge habitat is broader in woodland habitat next to farmland than it is in woodland next to the road. Similarly, most invertebrates captured were found within the woodland at an edge width of $15 \mathrm{~m}$ along the roadside and $35 \mathrm{~m}$ along the farmland. On the other hand, the Ornate rice frog (Microhyla ornate), which typically resides and forages in dim and humid environments, avoids edges. The edge effect results in this paper are applied in a model for determining ecologically critical road density. The estimation of edge width and critical road density obtained in this study can be applied during road planning and design to assess the potential effects of habitat conversion during road construction.
\end{abstract}

Keywords: edge effects, road density, construction, gray wolf, Kinmen Island.

\section{Introduction}

Highly accessible transportation systems stimulate regional economic development, but a high density of roads is greatly destructive to regional ecosystems. Extensive road networks may lead to more road kills, change of hydrologic flows, habitat fragmentation, disruption of natural streams, higher human access, more and small fires, and decreased habitat quality (Forman et al. 2003). Furthermore, the impact of road construction may be detrimental to the integrity of adjacent ecosystems and destroy an interior species' habitat (Reed et al. 1996). Road construction creates two strips of ecologically distinct area, edge, with micro-climatic conditions, such as light penetration, soil moisture, temperature, humidity, and wind speed, which differ from the original landscape (Gehlhausen et al. 2000). The major impacts of a newly created edge on adjacent vegetation are: direct damage to plants; changes in evapotranspiration, trophic circulation, and dissolution of materials; increase of pollen and plant seed dispersal; and disturbance of habitat soils (Harper et al. 2007). The edge may also change vegetation structure by introducing alien species, increasing the density of seedlings, increasing shrub coverage, and enhancing species abundance, thereby affecting the sustainability of some plant and animal species populations (Gehlhauson et al. 2000). On cool days, the heat of the road surface absorbing solar radiation can attract amphibians and snakes (Forman et al. 2003). Non-native plants gradually invade the natural area, starting from the edge (Parendes, Jones 2000), further altering the habitat and as a result the distribution of animals.

Increased disturbances from traffic may not repel edge species which can tolerate disturbances but may repel interior and sensitive species. Without proper mitigation measures, populations of interior species may decrease considerably, even to the point of local extinction. The widths of edge effects vary depending on species, habitat types, geological environments and vegetation structure (Gehlhausen et al. 2000). Changes in microclimate may extend 50-80 m into the forest (Young, Mitchell 1994; Stevens, Husband 1998; Burke, Gibbons 1995) and cause the death of trees within 60-100 m adjacent to grassland or 40-60 m next to revegetated forest (Mesquita et al. 1999). The invasion of exotic plant seeds may extend $30 \mathrm{~m}$ into the interior of an undisturbed forest (Cadenasso, Pickett 2001) such that exotic plants may cover a $40-60 \mathrm{~m}$ wide area along the edge (Gehlhausen et al. 2000). The microclimate and composition of plants along the edge may also affect the animal species composition. For example, the

Corresponding author: Shyh-Chyang Lin

E-mail: sclin@nqu.edu.tw 
effect of edges on small mammals in Brazilian Atlantic forest habitat ranges from 120-160 $\mathrm{m}$ from the forest edge (Stevens, Husband 1998), but in tropic Queensland, the edge effects on small mammal communities can extend to 200-500 m (Laurance 1994). By meta-analysis, it is found that the ecological effects of infrastructure on bird populations can extend up to $1 \mathrm{~km}$ and on mammals populations can extend up to $5 \mathrm{~km}$ (Benitez-Lopez et al. 2010). Even interior forest invertebrates (beetles) can be affected by the edge as far as $1 \mathrm{~km}$ (Ewers, Didham 2008). Amphibians and reptiles are also vulnerable to alteration of landscapes near their wetland habitats. The impact of forest edge next to non-forested wetlands may extend 159-290 m for amphibians (Semlitsch, Bodie 2003; Burke, Gibbons, 1995) or 127-289 m for reptiles (Semlitsch, Bodie 2003; Semlitsch 1998). Salamander habitats, in a forest adjacent to forest management roads or abandoned logging roads, decrease in suitability by $28.6 \%$ to $36.9 \%$, and the abundance of the species is affected up to $35 \mathrm{~m}$ on either side of the roads (Semlitsch et al. 2007). Larger mammals are generally more sensitive to the edge and have larger edge effect distances (Benitez-Lopez et al. 2010), which can be as broad as 3,000 $\mathrm{m}$ (Kinnaird et al. 2003).

However, the above surveys and studies were all conducted in ecologically stable environments with established edges. It is predictable that short-term edge effects would be more extensive in an ecosystem adjacent to roads under construction compared to previously constructed roads. A distinct ecological edge habitat is created on either side of the road as construction commences. The disturbance of construction activities along with changes in microclimate instantly affect terrestrial animals' distribution by attracting or repelling them. Although road construction typically lasts only 1-2 years, it may generate greater disturbance than established roads, such as noise from heavy equipment, large quantities of earth moving,

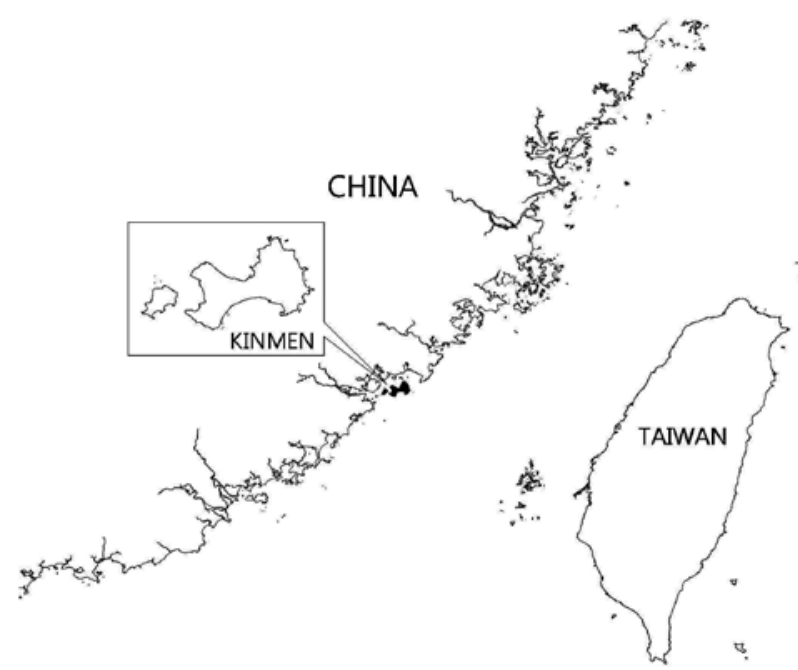

Fig. 1. The map of vicinity of Kinmen islands and large-scale vegetation clearing. These activities may create a broader edge effect zone and have a greater effect on interior or sensitive species compared to established roads, such that local extinction of sensitive species is more probable during road construction.

Few studies have been conducted with regards to the edge effect of roads under construction. Without these data, road designers and planners will not be able to devise mitigation measures and construction practices that minimize ecological impacts. The effectiveness of ecological mitigation measures can only be properly evaluated when edge effects are understood. This research tries to determine the ecological effects of road construction on rodents, invertebrates, amphibians and other species at varying edge widths, and to determine the relationship between edge area and road density within the broader region. A model of critical road density, the highest road density in which species populations can be maintained for a considerable period of time without a substantial reduction of the local population due to roads, was also developed for designated species. With the application of these findings, transportation planners can use reliable evaluation methods to assess potential ecological impacts on species of interest.

\section{Scope of investigation}

The investigation of this research was carried out on Kinmen Island (a county island of Taiwan) where is located off the coastline of Xiamen, Fujian Province, China (Fig. 1), with a total area of $150.5 \mathrm{~km}^{2}$, and has a human population of approximately 50,000. For defence purposes, Kinmen's vegetation was intensively rehabilitated during the period of Martial Law from approximately 1950 to 1990, and became ideal habitat for various species, especially migratory birds. Since the dissolution of martial law in 1992, Kinmen has been experiencing extensive and continuous development and construction. Most roads have been widened or rehabilitated, and some new roads have been constructed, impacting woodlands or other vegetated areas. Since the island is relatively small, the rapid expansion of the road system has had a substantial impact on the local ecosystem. One of the roads used to be under construction, called University Road, connects National Quemoy University (NQU) with Wuan Dau West Road (WDW), and is the subject of this research. The road construction was funded by the county government to provide additional access to the school for students and local residents. This road is similar to other Kinmen county roads, with standard engineering design and expected low traffic volumes. Construction commenced on June 27, 2006, with total a length of $337 \mathrm{~m}$ and a width of $15 \mathrm{~m}$, including a pedestrian sidewalk on one side. The road bisected a 9.97 hectare area of woodland into two sections (Fig. 2). The eastern section of the woodland is 4.04 hectares, and the 
western section, where the investigation was conducted, is 5.01 hectares. The woodland canopy is mostly covered by beef woods or Australian pine (Casuarina equisetifolia) with dispersed Acacia confuse and Eucalyptus robusta. The subcanopy includes Melisa azedarach, Litsea glutinosa, Albizzia lebbeck, and Celtis sinensis, with lesser numbers of Pinus massoniana, Cinnamomum camphora, Sapium sebiferum, Vitex negundo, and Dodoneae viscose. The understory species are mainly Lantana camara and Murraya paniculata, with dispersed Asparagus cochinchinensis, Berchemia lineate, Elaeagnus oldhamii, Maytenus diversifolia, Pteris semipinnata, Lygodium japonicum, Cocculus orbiculatus, and Commelina auriculta. Of the 107 total plant species, 72 are native; 1 species is endemic, 1 endangered, and 3 are rare. The western woodland was selected for study due to its larger area compared to the eastern woodland. The western woodland was bounded to the east by the road under construction, to the south by the WDW road, and to the west and northeast by farmlands. Surrounded by roads and farmlands, the woodland became an ideal site to evaluate the edge effects of both road construction and farmlands. The results allowed us to determine the width of edge effects for particular species and to identify how those species respond to road and farmland edge. Finally, the ecological effects of the road network on the regional ecosystem can be evaluated using the survey results and statistical analysis.

\section{Methods}

To cover the full extent of the road edge effect zone, it was necessary to access the inner area of the woodland; therefore, ten transects of varying length, each $30 \mathrm{~m}$ apart and perpendicular to the road, were created by clearing some obstacles and dead woods. Along each transect, one wire-mesh trap and one pitfall $(10 \mathrm{~cm}$ in diameter and $10 \mathrm{~cm}$ depth) were placed at $10 \mathrm{~m}$ intervals beginning at the edge of the land cleared for construction and extending into the core of the woodland then the other end of the woodland. The research commenced on July 1, 2006 and concluded on January 7, 2007 and each transect was surveyed 16 times. Three days were needed for each survey, and animals were given a two-week recovery period. On the evening of the first day, bait (consisting of sweet potato dipping peanut butter) was put into the wire-mesh traps and pitfalls were filled with fresh water. The next morning (around $7 \mathrm{AM}$ ), researchers checked for captured animals. Small mammals (mostly rodents) were marked with paint and then released at the trap location. A large number of invertebrates trapped in the pitfalls died. They were marked and brought back to the laboratory for identification. After releasing the captured animals, the wiremesh traps were washed thoroughly to eliminate animal odours. On the evening of the same day, the traps were

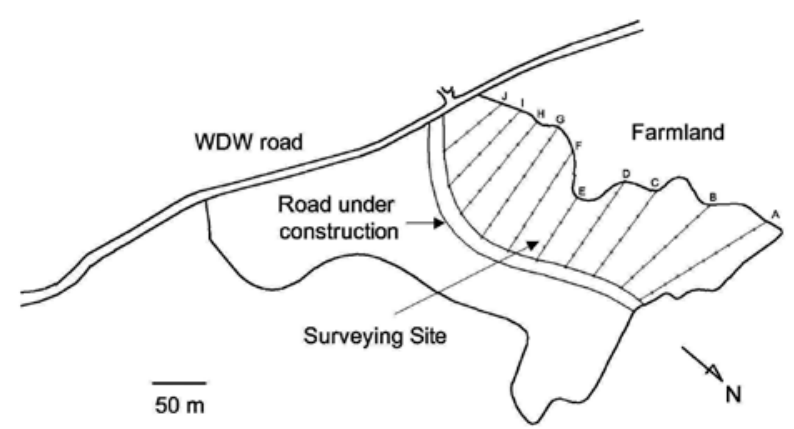

Fig. 2. The configuration of study site

refilled with bait and the pitfalls were refilled with water. Traps and pitfalls were again checked on the morning of the third day, and captured animals were treated in the same manner as the previous day. At this point, the traps were removed and pitfalls covered until the next survey round. During the period of investigation, two transects ( $\mathrm{I}$ and $\mathrm{J}$ ) were affected by construction activities, and were at first shortened and later excluded during statistical analysis. Because each phase of road construction causes different ecological impacts, it was necessary to carry out surveys during each phase. Surveys were continued until three transects (E, F, and G) were destroyed by construction, at which point the surveys were discontinued. The major stages in road construction during our surveys included excavation, ground clearing, grading and ditch construction, with excavation possibly creating the most disturbance to the adjacent habitat. On the other hand, ditch construction creates an artificial barrier that may prevent or inhibit certain animal species from crossing the road.

\section{Results and analysis}

During the construction period, the most common mammals captured were the Brown country rat, the House shrew (Suncus murinus) and the Red-bellied tree squirrel (Callosciurus erythraeus). Pitfalls collected a large number of invertebrates and some amphibians. On the other hand, spiders were singled out for further analysis since the number captured was high and their ecological traits are distinct from other invertebrates. Nine birds were also, unexpectedly, captured in wire-mesh traps during the investigation. The type and number of species captured are listed in Table 1.

Table 1. Species and number captured in 16 surveys

\begin{tabular}{|c|c|c|c|c|c|c|c|c|}
\hline $\begin{array}{l}\mathscr{\Xi} \\
\stackrel{\Xi}{\Xi} \\
\text { की }\end{array}$ & 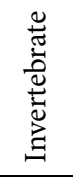 & 莺 & 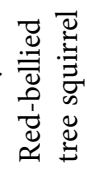 & 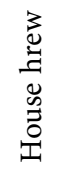 & $\begin{array}{l}\ddot{\tilde{u}} \\
\text { के. }\end{array}$ & 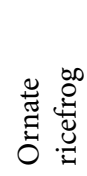 & 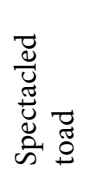 & 洸 \\
\hline Captivity & 919 & 372 & 7 & 51 & 92 & 21 & 28 & 9 \\
\hline
\end{tabular}




\subsection{The effects of road construction on Brown country rat distribution}

Brown country rats are widely distributed in mid and low latitude agricultural fields and grasslands in Taiwan. In Kinmen, the Brown country rat is the dominant small mammal in the farmlands (Chen 2003) and they were captured with great frequency during the research. In tabulating the collected data (results are shown in Figure 3), we found a considerably higher capture rate (the average number captured per survey night) of the rodents near the road and farmland edges as opposed to the inner woodland. In this case, the resources and microclimate of the edge may encourage the rodents to forage where they are captured by the wire-mesh traps. However, the locations closest to the road $(0 \mathrm{~m})$ had a lower capture rate than the next closest locations $(10 \mathrm{~m})$. This suggests that the road construction activities deter the rodents from getting too close to the job site. To determine the width of the road's edge effect $(d)$, correlation analysis was applied and $p$-values were calculated by taking $d=5 \mathrm{~m}$, $15 \mathrm{~m}$, and $25 \mathrm{~m}$ with a $95 \%$ confidence level. Since transects I and J were very short (less than $30 \mathrm{~m}$ ) and later destroyed, and transect $\mathrm{E}$ was only $50 \mathrm{~m}$ from the opposite side of the woodland, they were excluded from the statistical analysis. The lengths of the other transects were between $70 \mathrm{~m}$ and $100 \mathrm{~m}$ and, therefore, the length used for analysis of the road's edge effect was $50 \mathrm{~m}$ (from road edge to $50 \mathrm{~m}$ inside woodland); lengths greater than $50 \mathrm{~m}$ would have entered the edge area of the other side (woodland/farmland side) of the woodland. We can not rule out the possibility that transects longer than $50 \mathrm{~m}$, the opposite edge (woodland/ farmland edge) may affect the character or widths of road edge effects. The results from statistical analysis may show if this situation exists.

To determine the widths of edges, the Point-biserial correlation method was employed. The Point-biserial correlation is mathematically equivalent to the Pearson (product moment) correlation that is, if we have one continuously measured variable $X$ (here is the width of edge) and a dichotomous variable $Y$ (here is edge or interior), $r_{X Y}=r_{p b}$ (point biserial correlation coefficient). This can be shown by assigning two distinct numerical values to the dichotomous variable. The Point-biserial correlation is

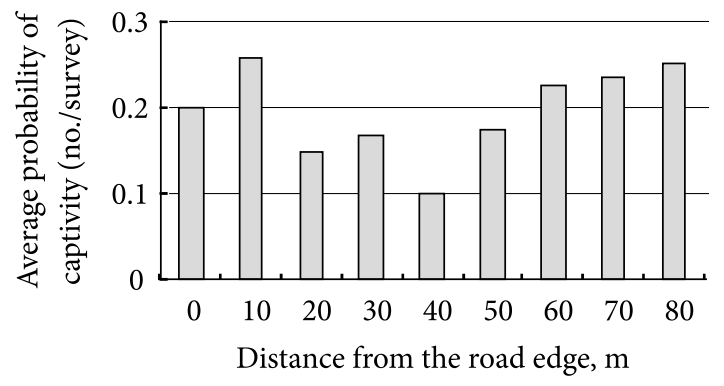

Fig. 3. Average probability of Brown country rat capture along the road edge analogous to a "t-test", which is the statistical test conducted to obtain the relationship between a categorical independent variable (such as gender: male, female) and a continuous dependent variable. To calculate $r_{p b}$, assume that the dichotomous variable $\mathrm{Y}$ has the two values 0 and 1 . If we divide the data set into two groups, group 1 which received the value " 1 " on $Y$ and group 2 which received the value " 0 " on $\mathrm{Y}$, then the point-biserial correlation coefficient can then be calculated:

$$
r_{p b}=\frac{M_{1}-M_{0}}{s_{n}} \sqrt{\frac{n_{1} n_{0}}{n^{2}}},
$$

where $s_{n}$ is the standard deviation and $M_{1}$ denotes the mean value on the $\mathrm{X}$ and $M_{0}$ being the mean value on $\mathrm{Y}$, and $n_{1}$ and $n_{0}$ are the number of $\mathrm{X}$ and $\mathrm{Y}$ (Glass, Hopkins 1996). For the $50 \mathrm{~m}$ transects beginning at the road edge, the results of point-biserial correlation analysis (Wang 2005) on Brown country rat captures are shown in Table 2. The $d$ value with the highest $r$ and the lowest $p$-value represents the point along the transect that has the greatest edge effect on a particular species. Statistically, $d=15 \mathrm{~m}$ has the highest $r(0.423)$ and the lowest $p$-value (0.0026), so this distance can be identified as the distance from edge at which the greatest greater number of individuals displayed an association with the road edge.

Table 2. Results of correlation analysis for edge effects

\begin{tabular}{ccccc}
\hline & \multicolumn{2}{c}{ Brown country rat } & \multicolumn{2}{c}{ invertebrates } \\
\cline { 2 - 5 }$d(\mathrm{~m})$ & $\begin{array}{c}\text { Road } \\
\text { edge effect } \\
\mathrm{p}(\mathrm{r})\end{array}$ & $\begin{array}{c}\text { Farmland } \\
\text { edge effect } \\
p(\mathrm{r})\end{array}$ & $\begin{array}{c}\text { Road } \\
\text { edge effect } \\
p(\mathrm{r})\end{array}$ & $\begin{array}{c}\text { Farmland } \\
\text { edge effect } \\
p(\mathrm{r})\end{array}$ \\
\hline \multirow{2}{*}{$0 \sim 5$} & $\begin{array}{c}0.1229 \\
(0.183)\end{array}$ & $\begin{array}{c}0.075 \\
(0.244)\end{array}$ & $\begin{array}{c}0.016 \\
(0.333)\end{array}$ & $\begin{array}{c}0.493 \\
(0.003)\end{array}$ \\
\hline \multirow{2}{*}{$0 \sim 15$} & 0.0026 & 0.013 & 0.005 & 0.483 \\
& $(0.423)$ & $(0.369)$ & $(0.389)$ & $(0.007)$ \\
\hline \multirow{2}{*}{$0 \sim 25$} & 0.0149 & 0.006 & 0.039 & 0.206 \\
& $(0.336)$ & $(0.414)$ & $(0.275)$ & $(0.141)$ \\
\hline \multirow{2}{*}{$0 \sim 35$} & 0.0182 & 0.002 & 0.218 & 0.041 \\
& $(0.324)$ & $(0.478)$ & $(0.124)$ & $(0.294)$ \\
\hline \multirow{2}{*}{$0 \sim 45$} & - & 0.042 & - & 0.197 \\
& & $(0.295)$ & - & $(0.146)$ \\
\hline
\end{tabular}

On the opposite end of each transect lies farmland, where the woodland edge forms an ecological gradient with less contrast than that of the road/woodland edge. Farmland also attracts more rodents than the road construction zone. The result shows the rate of capture for Brown country rats along transects beginning at the woodland/farmland edge. As with the road/woodland results, more rats were caught in traps closer to the edge. Utilizing the same statistical analysis method but excluding transect A (which did not extend all the way to the farmland), six transects were analyzed with $d=0 \mathrm{~m}$ marking the boundary of woodland/ farmland. Table 2 shows the results of the analysis for the 
$50 \mathrm{~m}$ transects beginning at the farmland edge. The $r$ and $p$-value are highest $(0.478)$ and lowest $(0.002)$, respectively, at $d=35 \mathrm{~m}$. This result illustrates that the rats show an edge effect further in the woodland interior compared to the edge effect adjacent to a road/woodland edge.

\subsection{Ecological edge effects of road construction on invertebrates}

Invertebrates are typically basal species in a trophic system and may be an important source of nutrients for other species in the ecosystem. They are usually important and abundant members in an ecosystem. Due to their low tolerance to disturbance, the species composition and population sizes of the invertebrate community can be ideal indicators in evaluating the impacts of disturbances on an ecosystem. Little is known about the effects of road construction, including air pollution, vibration, noise, contamination, and waste water, on the distribution and existence of individual invertebrate species or populations, or how the open spaces created by roads may lure certain insect species to road/habitat edges.

To determine the impacts of road construction on the distribution of invertebrates, pitfalls filled with fresh water were placed along transects and checked periodically, as described above. A total of 919 individual invertebrates were collected. The average capture rates along the road/woodland transects are shown in Figure 4. The results show that capture rates were relatively high along the road/woodland edge. This is presumably because most invertebrate species are phototaxic and are drawn to the edge for light and resources. Correlation analysis shows that $d=15 \mathrm{~m}$ from the road construction site has the highest $r(0.389)$ and the lowest $p$-value (0.005) (Table 2).

Similarly, we analyzed the effects of the woodland/ farmland edge on the distribution of invertebrates and the invertebrate capture results. The results of correlation analysis are shown in Table 2. With the highest $r$ (0.294) and the lowest $p$-value (0.041), the width of the ecological edge within the woodland adjacent to farmland is $d=35 \mathrm{~m}$ and is statistically significant. This may be explained by the woodland invertebrates' attraction to the microclimate, light or resources in a broader area near the woodland/ farmland edge, where the habitat contrast is much lower than at the road/woodland edges.

\subsection{The ecological edge effects of road construction on other species}

(1) House shrew

House shrews are more populous than other small mammals in Kinmen (Changjien 2000), but are commonly found in residential and developed areas rather than farmland areas (Lin 1982); thus, it was unexpected to capture this species during this study. However, differences between agricultural, woodland and human habitat on Kinmen are often indistinct, and there may be niches in farmlands and woodlands which House shrews can occupy and persist.

A total of 51 house shrews were captured, with the distribution of captures widely dispersed, as shown in Figure $5 \mathrm{a}$. Based on these limited findings, any conclusions about the correlation between the House shrew's habitats range and attraction to construction site edges is imprudent. We know, however, that the species is a generalist (Lin 1982) and therefore that either edge or interior of the woodland could be suitable habitat.

\section{(2) Ornate rice frog}

In this research, animals captured by pitfalls - other than invertebrates - were mostly Ornate rice frogs (Microhyla ornata) and spectacled toads (Bufo melanosticus). Relatively fewer individuals of these 2 species were captured, and the results are not statistically significant. However, by observing the capture locations, it may be possible to draw some conclusions regarding the species, response to road construction.

The distribution of Ornate rice frog captures is shown in Figure 5b. Only 1 Ornate rice frog was captured along road/woodland edge; all others were captured at distance greater than $10 \mathrm{~m}$ from the road edge (including the last survey point along transect $A$, which is still in the interior portion of the woodland). Rice frogs favor humid and dark environments (Lu et al. 1990) and are known to be interior species, and avoid edges with a relatively dry and bright microclimate. Because the core areas of woodlands or forests appear to be their preferred habitat, new road construction will push the species from the newly formed edge and into the remaining interior habitat. High density road networks would reduce the interior area of natural habitat and, therefore, be detrimental to their population persistence.

\section{(3) Spectacled toad}

Although abundant in Kinmen, relatively few spectacled toads were captured, and no clear pattern is evident in their capture locations (Figure 5c). Based upon prior studies, the spectacled toad is a generalist which migrates or forages over both developed and natural areas (Digital

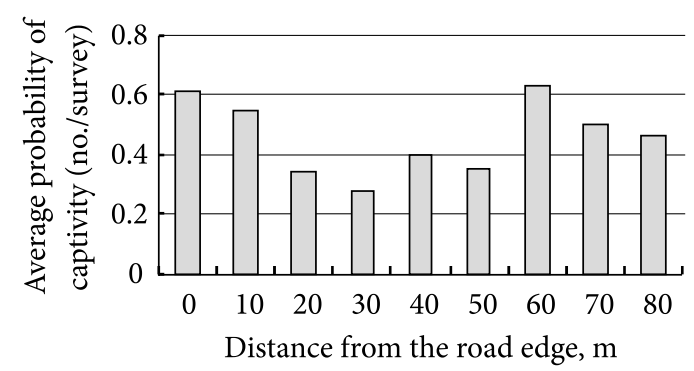

Fig. 4. Average probability of capture of invertebrates 
Museum of Zoology). The effects of road construction on this species cannot be determined based on these findings.

\section{(4) Spiders}

The reason that we singled out spiders for analysis is that spiders are important invertebrate predators in the terrestrial ecosystem (Woinarski et al. 2002) and exhibit distinct habitat preferences (Tso et al. 2005). There are 22 families and 151 species of spiders known to occur in Kinmen (Tso 2004). The spiders collected by pitfalls are numerous and their distribution is widely dispersed (Figure 5d). This investigation trapped only ground spiders, which are more mobile than bush or canopy species. However, it is found that forest understory and bush areas have the most abundant and diversified spider populations (Chen, Tso 2004), and this may explain that in this study, spiders were collected both along the edge (which is dominated by bushes) and in the interiors of the woodland (forest understory).

Transects I, J and E were excluded from statistical analysis because of their short length. The distance between adjacent transects is $30 \mathrm{~m}$ and the interval between each survey location along a transect is $10 \mathrm{~m}$. On one side of each location, a wire-mesh trap is placed, and on the other, a pitfall is placed. (a): Locations of house shrew capture where circles $(\bullet)$ are the capture locations. (b): a)

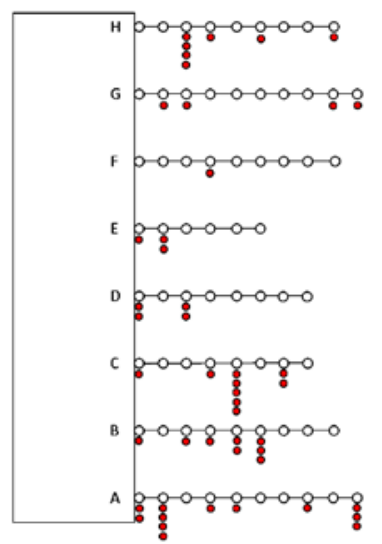

c)

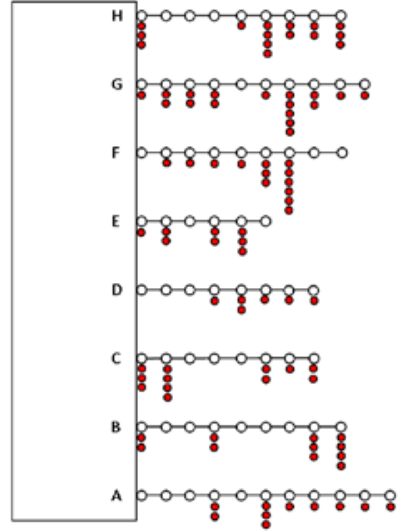

b)

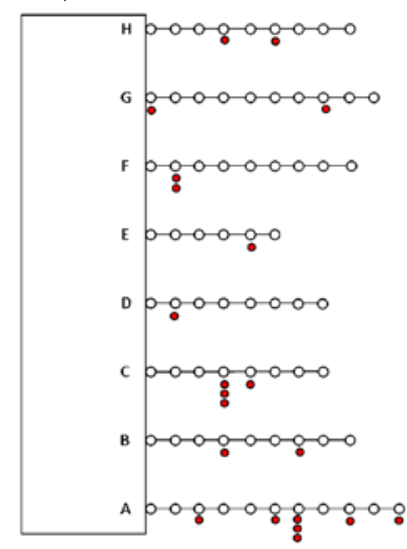

d)

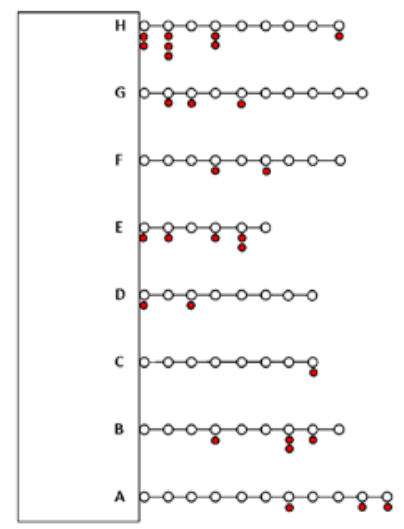

Fig. 5. Distribution of transects and survey locations
Locations of ornate rice frog capture where circles are the capture locations. (c): Locations of Spectacled toad capture where circles are the capture locations. (d): Locations of spider capture where circles are the capture locations.

\section{The impacts of the road network on the regional ecosystem}

To determine the effects of road construction on a regional ecosystem, it is necessary to investigate and determine the scale of ecological edge effects of road construction, both during and after construction. With edge effect width and road density information, it is possible to assess the proportion of edge within a regional landscape and the total area of remaining habitat for interior species. This will allow evaluation of appropriate mitigation measures during the road planning process.

Assuming that the roads in a region are laid out in a regular, grid-like pattern, as shown in Figure 6 (Lin 2006), the road density, $r$, can be obtained as

$$
\rho=\frac{2 L}{L^{2}}=\frac{2}{L},
$$

where $L$ denotes the length of road in each direction within the unit area (Fig. 6). The ratio of edge area to total area of the region $(\gamma)$ (including the area of the roads themselves) can then be calculated as

$$
\begin{aligned}
& \gamma=\frac{(w+2 d) \cdot 2 L-(w+2 d)^{2}}{L^{2}}= \\
& (w+2 d) \cdot \rho-(w+2 d)^{2} \cdot\left(\frac{\rho}{2}\right)^{2}
\end{aligned}
$$

where $w$ denotes road width and $d$ is the width of edge (Fig. 6). Equation (2) also represents the relationship between road density and edge area ratio in the regional landscape. A numerical relationship between road width, the ratio of edge area and road density can then be obtained as shown in Figure 7, in this case using $w=15 \mathrm{~m}$ and $d=20 \mathrm{~m}, 40 \mathrm{~m}, 80 \mathrm{~m}$, respectively. This figure shows that $\gamma$ and $r$ tend to have a linear relationship, and lower $d$ values result in lower $\gamma$ values.

If we take road width $w=20 \mathrm{~m}$, which is typical for secondary roads, and use the edge effects widths calculated for various species, it is possible to assess the ecological

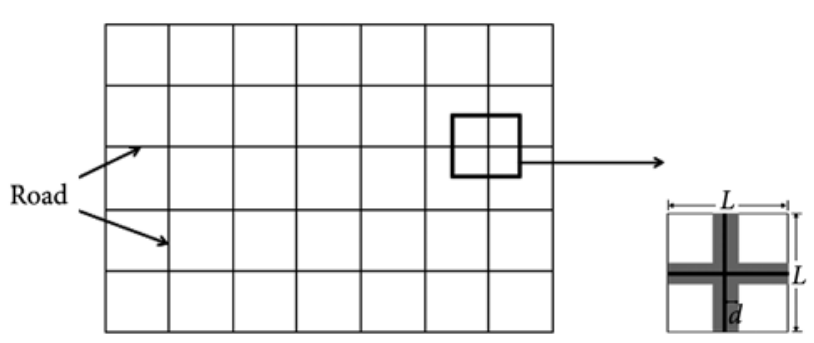

Fig. 6. Square grid layout of road network. Within each unit area, the edge effect of roads is in gray strips 
impact of road density on the species on a regional scale. We can define $\rho_{0}$ as the road density at which no interior habitat is left and the natural area is completely replaced by edge habitats. In the case of amphibians, the edge width is $d=25$ m (Demaynadier, Hunter 1998; Semlitsch et al. 2007), and the model yields $\rho_{0}=28.6 \mathrm{~km} / \mathrm{km}^{2}$. For most small mammals, $d=200 \mathrm{~m}$ (Laurance 1994) and $\rho_{0}=4.8 \mathrm{~km} / \mathrm{km}^{2}$; for large mammals, $d=3 \mathrm{~km}$ (Kinnaird et al. 2003) and $\rho_{0}=0.33$ $\mathrm{km} / \mathrm{km}^{2}$. For interior species, however, $\rho_{0}$ is not the critical road density, but rather the road density at which all habitats are edge habitat and no interior habitat exists.

\section{Derivation and testing of critical road density}

A critical road density $\rho_{c r}$ for a region is defined as the highest road density at which populations of a particular species can be maintained for a considerable period of time without significant ecological repercussions due to roads. With the application of this information, transportation planners can use reliable evaluation methods to assess potential ecological impacts on target species. The critical road density for designated species can be determined based on the minimum territory required, $A_{m}$, for a population of the species to persist. Suitable habitat is represented by the white areas (i.e., non-road and non-edge) in Figure 6. Figure 6 shows the relation between $L$ and $A_{m}$ as

$$
L=2 \times \sqrt{\frac{A_{m}}{4}}+(w+2 d) .
$$

Utilizing equation (1) that $L=\frac{2}{\rho}$, Equation (3) yields

$$
\frac{2}{\rho_{c r}}=\sqrt{A_{m}}+(w+2 d) .
$$

Hence,

$$
\rho_{c r}=\frac{2}{\sqrt{A m}+(w+2 d)} .
$$

Equation (5) implies that each area is encompassed by road edge is $A_{m}$.

It is necessary to test the applicability of $\rho_{c r}$ using existing ecological data on the width of edge and territory of a specific species. The relationship between gray wolf packs and road density has been thoroughly studied (Mech 1970; Thiel 1978, 1985; Mech 1989; Mladenoff et al. 1995; Wydeven et al. 2001). The data obtained from the above studies can be used to assess the validity of critical ecological road density as derived in this paper. In the Great Lakes region, Wydeven et al. (2001) found that areas occupied by wolf packs had average road densities of $0.23 \mathrm{~km} / \mathrm{km}^{2}$. Similarly, an independent investigation in the Minnesota-Wisconsin border region carried out by Frair (1999) concluded that average road density in wolf territory was $0.25 \mathrm{~km} / \mathrm{km}^{2}$ and that road density was the best predictor of suitable wolf habitat. Another researcher (Unger 1999) showed that wolves selected den sites in

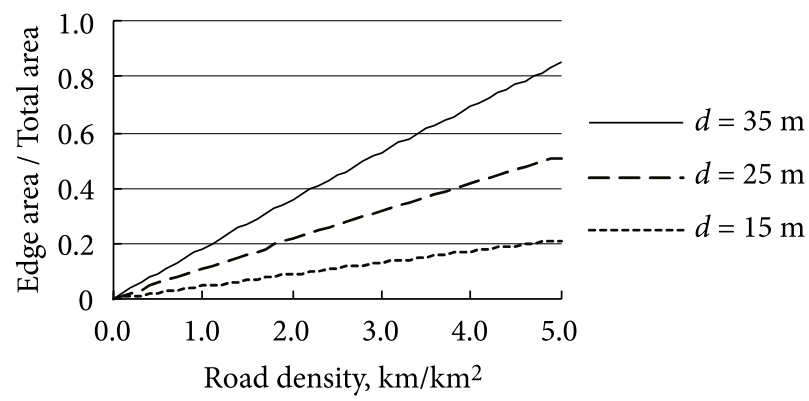

Fig. 7. Relationship between the edge area/total area ratio and road density with varying edge widths

roadless or low road density areas and dens were generally located more than $1 \mathrm{~km}$ from improved roads. These data allow us to evaluate the critical road density model by letting $\rho_{c r}=0.24 \mathrm{~km} / \mathrm{km}^{2}, w=0.1 \mathrm{~km}$, and $d=1 \mathrm{~km}$, and comparing the results with the actual territory of gray wolf packs. A wolf pack's territory may cover $51-307 \mathrm{~km}^{2}$ (Wisconsin Department of Natural Resources 2009) and the core of its territory is on average $35 \mathrm{~km}^{2}$ (Jedrzejewski et al. 2007). It is safe to assume the minimum territory of a wolf pack to be $35-51 \mathrm{~km}^{2}$. Substituting $\rho_{c r}=0.24 \mathrm{~km} / \mathrm{km}^{2}$ into Equation (5) yields $A_{m}=38.9 \mathrm{~km}^{2}$, which falls reasonably within the range of the minimum territory of gray wolf packs as described above. As can be seen, the critical road density $\rho_{c r}$ can be a useful indicator in regional road planning when $A_{m}$ is known for a target species. By determining $\rho_{c r}$ and $A_{m}$, transportation planners will be able to assess how road network configurations at regional or landscape scales may affect the persistence of target species.

\section{Discussion}

The ecological effect of roads on fragmented ecosystems is an important issue in ecological conservation. For road planning, the effects on various species, especially keystone or endangered species, must be studied thoroughly. This research has demonstrated a feasible means of evaluating ecological edge effect due to road construction and provides a model to approximate the potential impact of road networks on a regional ecosystem. Wire-mesh traps and pitfalls were used to capture small mammals, invertebrates, and amphibians along transects in woodland adjacent to a road on Kinmen Island. Based on the capture rate of this study, the Brown country rat can be characterized as an edge species that inhabits the woodland edge with an edge width of $15 \mathrm{~m}$ for the road/woodland edge and $35 \mathrm{~m}$ for the woodland/farmland edge. Even though edges generally provide a favourable environment for the rats, the abrupt change of landscape found at the road/ woodland edge ecologically decreases movements of edge species, and may reduce the distance Brown country rats will go from the edge. On the other hand, the edge adjacent to a more gradual change of landscape, such as farmland/ 
woodland, probably provides better habitat quality for the rats. Although the Brown country rat is a generalist, the disturbance of road construction can reduce the width of useful edge habitat for the species. Nevertheless, different small mammal species respond to edges differently, and the edge effect width obtained by this research for the Brown country rat differs from those for small mammals found by other researchers. Stevens and Husband (1998) found that both the mean number and diversity of small mammals increase as far from the edge as $120-160 \mathrm{~m}$ in two fragments of Brazilian Atlantic forest. In tropical Queensland, Australia, within 200-500 m of some heavily disturbed fragments the mammals that favored disturbed forest or edges increased (Laurance 1994). This is because the width of an edge is dependent upon factors such as latitude, landscape, vegetation, geology, road condition, and species. The vegetation cover of the survey site and the behavioural characteristics of the particular small mammal species studied in this research may be distinct from the other two studies cited above, and may be partially explain the differences in edge effect results. Road edges attract some invertebrates due to the alteration of the microclimate and in particular the availability of sunlight. In this research, many different species of invertebrates were collected, and it was not possible to determine the edge width for each individual species. The survey data shows that most invertebrates are found within $15 \mathrm{~m}$ of the road/woodland edge area and 35 $\mathrm{m}$ of the woodland/farmland edge and, therefore, most of them can be characterized as edge species. It is believed that some invertebrates are interior species and may stay away from edges; therefore, road construction reduces the useful habitat of these species. For the integrity of an ecosystem, species lower on the food chain, such as most invertebrates, must be investigated as they may have associations with higher level animals. The concentration of various invertebrates along the edge suggests that their predators are also more likely to forage along the edge, which in turn may lead to higher population densities, species richness and diversity within the edge habitat. It has been found that edge contrast and edge orientation may affect a species' response to an edge (Murcia 1995; Ries, Sisk 2004). Even the effects of edges are in forms of continuous response function (Ewers, Didham 2006), some clear contrasts can still be spotted. The distribution patterns of invertebrates and Brown country rats in this study allowed us to examine the effect of edge contrast. High edge contrast (road/woodland in this research) appears to reduce the abundance of these species even though the resources or microclimate may attract them to the woodland edge.

Although road construction may reduce the area of suitable edge habitat, creation of new edges by a new road provides additional favourable habitats for edge species and, thus, increases their population and potentially changes the natural evolution of the ecosystem. Road construction can increase the numbers of Brown country rats and invertebrates along the roadside. Without obvious predators in Kinmen, Brown country rats success may be attributable to increases in suitable roadside habitats and microclimates. A similar result by different survey method was reported by Rytwinski and Fahrig (2007), who found a higher relative abundance of White footed mouse (Peromyscus leucopus) and Short-tailed shrew (Blarina brevicauda) in rural high-road-density sites compared to rural low-road-density sites. They suggested that a road may create better habitat quality for the species or affect the species' predators. Another study concluded that roadside vegetation often provides favourable microhabitat for small mammal communities in the desert landscape (Bissonette, Rosa 2009). Based on the findings above, we may tentatively say "more roads, more rats".

Four species (house shrew, rice frog, toad, and spiders) displayed various responses to the road edge environment. The rice frog is an interior species exhibiting avoidance of the edge, and is the most sensitive to road construction. A study carried out in the Appalachian forest in the USA indicates that the width of edge effect for woodland salamanders extends $35 \mathrm{~m}$ from the road (Semlitsch et al. 2007). The microclimate, with reduced soil moisture near the roads, may be the leading cause of alteration of salamander distribution. Another study also found that the width of the edge was $20 \mathrm{~m}$ for red-backed salamanders (Plethodon cinereus) (deGraaf, Yamasaki 2002). The results of these two studies are quite similar to the phenomenon of road edge effect on rice frogs in our investigation. House shrews, toads and spiders, on the other hand, are generalists and may not be significantly affected by road construction or the influence of road networks.

In some cases, proper mitigation measures can reduce animal mortality by 97\% (McGuire, Morral 2000). For example, animal passages can connect habitats separated by roads (Bekker et al. 1995; Huijser, Bergers 2000) and provide routes for gene exchange (Forman et al. 2003). Raised road beds guide avian species to fly high over the road and avoid collisions with vehicles (Clevenger et al. 2003). Incorporating these measures and concepts into engineering design practice and specifications should be considered in each phase of road design to achieve more ecologically "friendly" construction.

There are examples of strategies that can be applied to reduce the impacts of traffic and road construction. The Trans-Canada Highway through the Rocky Mountain national parks is one example of the implementation of ecologically friendly practices (McGuire, Morrall 2000). In the project, wildlife exclusion fences and $2 \mathrm{~m}$ berms were installed to prevent most species from entering the job sites, to reduce traffic noise and visual disturbance and to divert runoff to nearby vegetated areas rather than into existing bodies of water. 


\section{Conclusions}

With the width of edge effect of road construction and home range (or territory size) of a particular species known, a critical road density $r_{c r}$ can be obtained that can be used to determine adequate habitat area for the species to persist. The critical road density for target (or rare) species would give us an idea whether the road density is too high for that particular species. The derivation of critical road density in this study is based on the assumption that the roads are uniformly distributed over a region, an assumption which yields a higher edge ratio than if roads were not uniformly distributed. If roads are concentrated in high population areas and fewer roads are in more natural areas, the regional edge ratio may be substantially lower, and may result in larger habitat blocks. Hence, while critical road density helps us understand the effects of new roads in a general sense, other considerations, such as providing large habitat blocks in high road density regions, may also be important considerations.

Regional critical road density derived in this research is a useful indicator for evaluating road network impacts and providing target species populations enough area to persist and keeping local ecosystems intact. Considering the substantial impacts of road construction on regional ecosystems, ecologically friendly planning, design and construction is needed to meet the needs of both human beings and nature.

\section{Acknowledgements}

The author is indebted to J. R. Lin, W. L. Lee, L. W. Hsu, P. L. Chen, L. S. Chang, and I. W. Lee for assistance in the field and to S. F. Lin of Taiwan Endemic Species Research and Conservation Center for identifying invertebrate species. This research is sponsored by the Ministry of Science and Technology of Taiwan, ROC (Grant no. 103-2621-M507-002).

\section{References}

Bekker, G. J.; Hengel, V. D. B.; van der Sluigs, H. I. 1995. Natuur over Wegen [Nature over motorways]. Ministry of Transport, Public Works and Water management, Delft, The Netherlands (in Dutch and English).

Benitez-Lopez, A.; Alkemade, R.; Verweij, P. A. 2010. The impact of roads and other infrastructure on mammal and bird populations: A meta-analysis, Biological Conservation 143: 307-1316. http://dx.doi.org/10.1016/j.biocon.2010.02.009

Bissonette, J. A. ; Rosa, S. A. 2009. Road zone effects in smallmammal communities, Ecology and Society 14(1): 27. [online], [cited 24 August 2009]. Available from Internet: http:// www.ecologyandsociety.org/vol14/iss1/art27/

Burke, J. J.; Gibbons, J. W. 1995. Terrestrial buffer zone and wetland conservation: a case study of freshwater turtles in a Carolina Bay, Conservation Biology 9: 1365-1369.
Cadenasso, M. L.; Pickett, S. T. A. 2001. Effect of edge structure on the flux of species into forest interiors, Conservation Biology 15(1): 91-97. http://dx.doi.org/10.1111/j.1523-1739.2001.99309.x

Changjien, L. W. 2000. Discovering wildlife in Liuchiu, Natural Conservation Quarterly 32: 44-49 (in Chinese).

Chen, C. S. 2003. Survey of mammals in Kinmen. Kinmen National Park Report. Taiwan (in Chinese).

Chen, K. C.; Tso, I. M. 2004. Spider diversity on Orchid Island, Taiwan; a comparison between habitats receiving different degrees of human disturbances, Zoological Studies 43: 598611 (in Chinese).

Clevenger, A. P.; Chruszcz, B.; Gunson, K. E. 2003. Spatial patterns and factors influencing small vertebrate fauna road-kill aggregations, Biological Conservation 10: 15-26. http://dx.doi.org/10.1016/S0006-3207(02)00127-1

deGraaf, R. M.; Yamasaki, M. 2002. Effects of edge contrast on redback salamander distribution in even-edged northern hardwoods, Forest Science 48: 351-363.

Demaynadier, P. G.; Hunter Jr., M. L. 1998. Effects of silvicultural edges on the distribution and abundance of amphibians in Maine, Conservation Biology 12(2): 340-352.

http://dx.doi.org/10.1046/j.1523-1739.1998.96412.x

Digital Museum of Zoology. 2012. National Taiwan University [online], [cited 2 October 2012]. Available from Internet: http://archive.zo.ntu.edu.tw/amph_index.asp?amph_ $\mathrm{id}=\mathrm{A} 0001$

Ewers, R. M.; Didham, R. K. 2006. Continuous response functions for quantifying the strength of edge effects, Journal of Applied Ecology 43: 527-536. http://dx.doi.org/10.1111/j.1365-2664.2006.01151.x

Ewers, R. M.; Didham, R. K. 2008. Pervasive impact of largescale edge effects on a beetle community, Proceedings of $\mathrm{Na}$ tional Academy of Sciences of the United States of America 105: 5426-5429. http://dx.doi.org/10.1073/pnas.0800460105

Forman, R. T. T.; Sperling, D.; Bissonette, J. A.; Clevenger, A. P.; Cutshall, C. D.; Dale, V. H.; Fahrig, L.; France, R.; Goldman, C. R.; Heanue, K.; Jones, J. A.; Swanson, F. J.; Turrentine, T.; Winter, T. C. 2003. Road ecology, science and solutions. Washington: Island Press.

Frair, J. L. 1999. Crossing paths: gray wolves and highways in the Minnesota-Wisconsin border region: Master Thesis. University of Wisconsin, Stevens Point.

Gehlhausen, S. M.; Schwartz, M. W.; Augspurger, C. K. 2000. Vegetation and microclimatic edge effects in two mixedmesophytic forest fragments, Plant Ecology 147: 21-35. http://dx.doi.org/10.1023/A:1009846507652

Glass, G. V.; Hopkins, K. D. 1996. Statistical methods in education and psychology. $3^{\text {rd }}$ ed. Boston: Allyn and Bacon.

Harper, K. A.; Mascarua-Lopez, L.; Macdonald, S. E.; Drapeau, P. 2007. Interaction of edge influence from multiple edges: examples from narrow corridors, Plant Ecology 192: 71-84. http://dx.doi.org/10.1007/s11258-006-9227-z

Huijser, M. P.; Bergers, P. J. M. 2000. The effect of roads and traffic on hedgehog (Erinaceus europaeus) populations, Biological Conservation 95: 111-116. http://dx.doi.org/10.1016/S0006-3207(00)00006-9

Jedrzejewski, W.; Schmidt, K.; Theuerkauf, J.; Jedrzejewska, B.; Kowalczyk, R. 2007. Territory size of wolves Canis lupus: 
linking local (Białowieża Primeval Forest, Poland) and Holarctic-scale patterns, Ecography 30(1): 66-76.

Kinnaird, M. F.; Sanderson, E. W.; O’Brien, T. G.; Wibisono, H. T.; Woolmer, G. 2003. Deforestation trends in a tropical landscape and implications for endangered large mammals, Conservation Biology 17(1): 245-257.

Laurance, W. F. 1994. Rainforest fragmentation and the structure of small mammal communities in tropic Queensland, Biological Conservation 69: 23-32. http://dx.doi.org/10.1016/0006-3207(94)90325-5

Lin, L. K. 1982. A study of terrestrial mammals in Taiwan: MS Thesis, Department of Biology, Tunghai University (in Chinese).

Lin, S. C. 2006. The ecologically ideal road density for small islands: the case of Kinmen, Ecological Engineering 27: 84-92. http://dx.doi.org/10.1016/j.ecoleng.2005.11.002

Lu, K. Y., Lin, J. Y.; Tsung, K. S. 1990. Taiwan's Wildlife Data Base (I) Amphibian (2). Ecological Report No. 8, Agriculture Commission. pp. 157 (in Chinese).

McGuire, T. M.; Morrall, J. F. 2000. Strategic highway improvements to minimize environmental impacts within the Canadian Rocky Mountain National Park, Canadian Journal of Civil Engineering 27: 523-532. http://dx.doi.org/10.1139/199-096

Mech, L. D. 1970. The wolf. Garden City: Natural History Press. http://dx.doi.org/10.2307/2426043

Mech, L. D. 1989. Wolf population survival in an area of high road density, The American Midland Naturalist 121(2): 387389.

Mesquita, R. C. G.; Delamônica, P.; Laurence, W. F. 1999. Effect of surrounding vegetation on edge-related tree mortality in Amazonia forest fragments, Biological Conservation 91: 129134. http://dx.doi.org/10.1016/S0006-3207(99)00086-5

Mladenoff, D. J.; Sickley, T. A.; Haight, R. G.; Wydeven, A. P. 1995. A regional landscape analysis and prediction of favorable gray wolf habitat in the Northern Great Lakes region, Conservation Biology 9: 279-294.

http://dx.doi.org/10.1046/j.1523-1739.1995.9020279.x

Murcia, C. 1995. Edge effects in fragmented forests: implications for conservation, Trends of Ecology and Evolution 10: 58-62. http://dx.doi.org/10.1016/S0169-5347(00)88977-6

Parendes, L. A.; Jones, J. A. 2000. Role of light availability and dispersal in exotic plant invasion along roads and streams in the H. J. Andrews Experimental Forest, Oregon, Conservation Biology 14: 64-75.

http://dx.doi.org/10.1046/j.1523-1739.2000.99089.x

Reed, R. A.; Johnson-Barnard, J.; Baker, W. L. 1996. Contribution of roads to forest fragmentation in the Rocky Mountains, Conservation Biology 10: 1098-1106.

http://dx.doi.org/10.1046/j.1523-1739.1996.10041098.x

Ries, L.; Sisk, T. D. 2004. A predictive model of edge effects, Ecology 85: 2917-2926. http://dx.doi.org/10.1890/03-8021

Rytwinski, T.; Fahrig, L. 2007. Effect of road density on abundance of white-footed mice, Landscape Ecology 22: 1501-1512. http://dx.doi.org/10.1007/s10980-007-9134-2
Semlitsch, R. D. 1998. Biological delineation of terrestrial buffer zones for pond-breeding salamanders, Conservation Biology 12(5): 1113-1119. http://dx.doi.org/10.1046/j.1523-1739.1998.97274.x

Semlitsch, R. D.; Bodie, J. R. 2003. Biological criteria for buffer zones around wetland and riparian habitats for amphibians and reptiles, Conservation Biology 17(5): 1219-1228. http://dx.doi.org/10.1046/j.1523-1739.2003.02177.x

Semlitsch, R. D.; Ryan, T. J.; Hamed, K.; Chatfield, M.; Drehman, B.; Pekarek, N.; Spath, M.; Watland, A. 2007. Salamander abundance along road edges and within abandoned logging roads in Appalachian forest, Conservation Biology 21(1): 159-167. http://dx.doi.org/10.1111/j.1523-1739.2006.00571.x

Stevens, S. M.; Husband, T. P. 1998. The influence of edge on small mammals: evidence from Brazilian Atlantic forest fragments, Biological Conservation 85: 1-8.

http://dx.doi.org/10.1016/S0006-3207(98)00003-2

Thiel, R. P. 1978. The status of the timber wolf in Wisconsin 1975, Transaction of Wisconsin Academy of Science and Arts Letter 66: 186-194.

Thiel, R. P. 1985. Relationship between road densities and wolf habitat suitability in Wisconsin, The American Midland Naturalist 113(2): 404-407. http://dx.doi.org/10.2307/2425590

Tso, I. M. 2004. Investigation of spider diversity in Kinmen, Kinmen National Park Report, Taiwan [online], [cited 20 November 2009]. Available from Internet: http://www.kmnp. gov.tw/ct/filesys/file/research/93-animal_paper_12.pdf (in Chinese).

Tso, I. M.; Tseng, L.; Chuang, C. Y.; Cheng, J. C. 2005. Diversity and community structure of spider in Yang-Ming San National Park, Journal of National Park (Taiwan) 15(1): 1-20 (in Chinese).

Unger, D. E. 1999. Timber wolf den and rendezvous site selection in northwestern Wisconsin and east-central Minnesota: M.S. Thesis, University of Wisconsin, Stevens Point. WI. 76 p.

Wang, W. D. 2005. Practice and applications of statistical data analysis with Excel. Taiwan: BS Culture Publisher Co. (in Chinese).

Wisconsin Department of Natural Resources [online]. 2009. [cited 20 September 2009]. Available from Internet: http://dnr. wi.gov/org/land/er/factsheets/mammals/wolf.htm

Woinarski, J. C. Z.; Andersen, A. N.; Churchill, T. B.; Ash, A. 2002. Response of ant and terrestrial spider assemblages to pastoral and military land use, and to landscape position, in a tropical savanna woodland in northern Australia, Austral Ecology 27(3): 324-333.

Wydeven, A. P.; Mladenoff, D. J.; Sickley, T. A.; Kohn, B. E.; Thiel, R. P.; Hansen, J. L. 2001. Road density as a factor in habitat selection by Wolves and other carnivores in the Great Lakes Region, Endangered Species UPDATE 18(4): 110-114.

Young, A.; Mitchell, N. 1994. Microclimate and vegetation edge effects in a fragmented Podocarp-Broadleaf forest in New Zealand, Biological Conservation 67: 63-72. http://dx.doi.org/10.1016/0006-3207(94)90010-8

Shyh-Chyang LIN is an associate professor with Department of Civil Engineering and Engineering Management at National Quemoy University, Taiwan. He has broad expertise which includes civil engineering, ecological engineering, island studies, and social network. He resides in Kinmen, an island county of Taiwan, and endeavours on island ecological conservation. He received presidential distinguished environmental award of Taiwan in 2005. 